\title{
Connotations and cultural significance of taking jade in Chu Dynasty before Qin Dynasty
}

\author{
Zhongyuan Li ${ }^{1,}$ \\ ${ }^{1}$ School of Fashion Wuhan Textile University, China Wuhan Hubei
}

Keywords: Chu Pre-Qin period; the jade use on clothes, Chinese jade culture, connotations and meanings.

\begin{abstract}
The thesis conducts its analysis from the pre-Qin Dynasty Jade Chu cultural characteristics in ancient China, under the prevailing discussion Chu Wu Ji cultural background, taking Chu jade unique artistic features, which come out of the pre-Qin and Chu socio-cultural characteristics. In fact, taking Jade embodies the social and cultural connotations and spiritual ethos. Chinese jade of Chu sate of Pre-Qin period due to its abundant cultural connotations and meanings, proses to be an essential element of traditional Chinese culture, which shows artistic and national features of traditional jade culture and can directly influence development of modern society and culture.
\end{abstract}

\section{Introduction}

Jade, a gem to the nation. Chinese jade, which owns prominent spiritual connotations on traditional Chinese culture also brings with itself profound national connotations in Chu culture at Pro-Qin period. By exploring cultural connotations of jade artifacts of Chu state in Pre-Qin period, conclusions can be draw that jade, as an important article for sacrificing use, plays an essential role in traditional Chinese culture and thus is a typical symbol of Chinese nationality as well as a symbol and a pillar to spiritual civilization. in China. Jade artifacts of Chu state are something of cultural representatives in terms of its internal cultural connotations.

\section{Jade as core element of sacrifice activity in Chu state of Pre-Qin period can be considered as internal culture representative.}

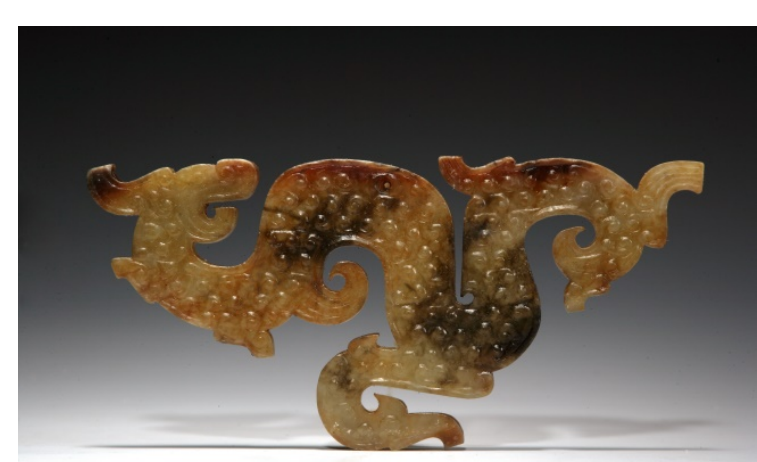

Solemness and decency of jade reflects national traits and spirits shaping of jade artifacts is rarely indulged in small things or details, but rather, it often appears to be solemn and decent, which does not only show the national spirits of Chu state at Pro-Qin period, but also implies minds and thoughts of the Chu people. As for culture and art., jade artifacts of Chu state usually are exquisite because of delicate workmanship. The craftsmanship of jade carving, with abundant imagination of craftsman, endows jade artifacts and decorations with characterization of

1 : The ERON Pelosi (unearthed tomb in artistic design. This is the deep internal connotation of jade culture of Chu state, which is a straight embodiment of its importance in Chu culture as a Jingzhou Xiong Jia Zhong) whole and can be as basic symbol of national spirits of the Chinese people. At the same time, meanings carried by jade also reflect national values in traditional Chinese culture.The flowing cloud pattern is an embodiment of internal cultural traits of jade artifacts of Chu state

Through an analysis of cultural and artistic characteristics reflected by jade artifacts of Chu state at Pre-Qin period from the perspective of pattern design of jade, artistic effect can be easily defined. The cloud pattern is flowing and smooth, showing exquisiteness and beauty of jade. Besides, the 
cloud pattern is more commonly used in jade accessories, which adds better hand feel and stronger artistic sense to those accessories and meanwhile reflects cautiousness and refined sensibility of Chu people. By analyzing interior personalities of Chu people, conclusions can be drawn that they put great emphasis on synchronous cultivation between personal character and exterior etiquette. Jade to some extent fully implies Chu people' sdignity, gracefulness and reasonableness. Pattern, shapes and design concepts of jade accessories objectively present geographical identity and internal traits of Chu culture development. ${ }^{1}$ Artistic features of jade accessories and deep connotations as well as appreciation value presented by pattern of jade accessories embody the profound "artistic beauty" and "qualified beauty".

Among all sub-cultural forms in Chu culture, the sorcery culture and the ceremonial culture, are essential symbolization of grave state events. Playing a significant role in culture development of Chu state, jade can show noble status of its owner and is granted with special deeply connotations in Pin-Qin period. Majestic sacrificing and ceremonial events usually put jade at a supreme status. Analyzing implications of jade of Chu state, distinctions among profound meanings of different jade pattern can be observed.

When observing Chu state and its culture from the perspective of progress of traditional culture, it is not difficult to find that of all features of jade culture of Chu, the pursuit for comprehensive development of morality and culture occupies a crucial place. Through analyzing applications of jade artifacts, they play a very important role in ceremonial and sacrificing activities. Ceremonial culture, except for emphasizing gracefulness ,it also highlights the internal personalities of human beings. This is the moral and cultural characteristics symbolized by jade Chu The Chu culture takes cultural etiquette as it root. While the jade accessory not only marks identity and personality of its owner, but also implies certain mores and degree of moral recognition. For example, weapons are usually with jade accessories of pattern of dragons or phoenixes which symbolize state spirits and main features of national culture.

\section{The artistic characteristics of jade wares show the cultural characteristics of Chu people}

Generally speaking, jade accessories of Chu state have two prominent features: solemnness and

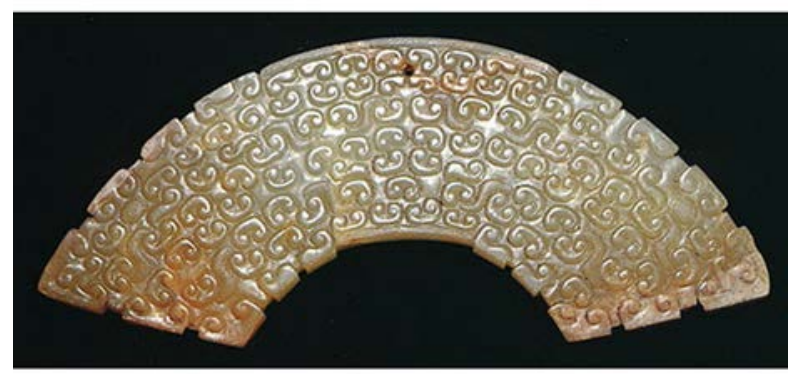
gracefulness implies openness and inclusiveness in human personality while delicacy and exquisiteness implies humbleness. The above two features manifest that jade reflects personality and inner quality of human beings and jade accessories bring with itself cultural connotations. As a token of individual' s social status, jade accessories usually adopt patterns describing imagined things ( for example, dragon, phoenix ,Kylin, etc ) . These

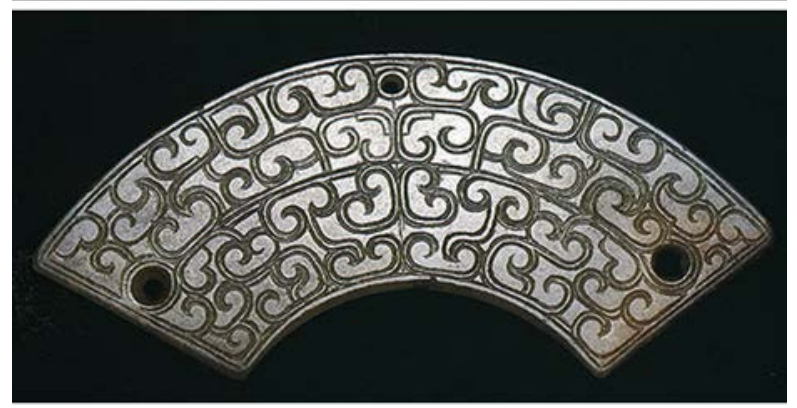
accessories on the one hand symbolize social status of people and on the other hand imply people's inner thoughts. Although jade is often carved with imagined animal totems, expert carving workmanship seems to bring life to those pictures, which inspires people's imagination and shows the "artistic beauty" of jade accessories. This is the essential characteristic of traditional culture

2 : Yu Huang (Ceng Houyi cemetery in Hubei) Warring States Period presented by jade artifacts of Chu state, while its cultural value is mainly embodied by aesthetics of jade accessories. Jade accessories of Chu state can reflect artistic creation and innovation of culture. Therefore, they are considered as a crucial cultural

\footnotetext{
${ }^{1}$ Lin Lin: a brief talk on Zhou Lizhong's jade system, Tai LAN world: late, 2014,page16-17
} 
element representing development of traditional Chinese culture.

In light of artistic patterns of jade artifacts of Chu state, the hollowed - out jade as a representative of jade culture, contains profound culture connotations. The hollowed - out jade, no matter its delicate carving workmanship or its artistic interior design, show the pursuit for appreciating value of "artistic beauty". So the artistic value of jade is fully unveiled. What' s more, the hollowed - out jade of Chu state, is not only a representation of the exquisite jade pattern but also embodies the appreciating capability of Chu people and their perception over beauty of art. In a word, the jade culture of Chu state at Pre-Qin period reflect Chu people's pursuit for art and is a presentation of culture traits and personalities of Chu people. At last, it also shows cultural characteristics and taste of Chu as well as its artistic traits and aesthetic preference.

\section{Jade pattern reflects the etiquette of Chu people}

As an important symbol of culture of Chu state, Yu Bi serves as a token for state sacrifice ceremony and foreign exchange. As a result, Yu Bi apparently shows the state honor, spirit and personality. Yu $\mathrm{Bi}$, in light of its appearance, is glossy and presents the color of clean white. The hole of a $\mathrm{Yu} \mathrm{Bi}$ in central area ,is suitable for the body of the $\mathrm{Yu} \mathrm{Bi}$ and is not only decent but also exquisite. If digging into deep connotations of $\mathrm{Yu} \mathrm{Bi}$, whiteness and transparency of it can be interpreted as Chu people' pure heart and their simplified thoughts over things as well as their rigorousness, whereas the smooth surface of $\mathrm{Yu} \mathrm{Bi}$ is an embodiment of clean and decent appearance of Chu people as well as their sense of state honor and national pride; meanwhile, it also reflects Chu people's love for peace and hatred towards martial behavior. The above interpretation is the basic culture connotation of jade of Chu state. The culture meanings of jade indirectly reflect Chu people's social personalities and mind activity over the way they treating things. This is an overall embodiment of culture of Chu state of Pre-Qin period and the spiritual value of itself. Cultural meanings of jade at the same time also the perfect integration between the Chu culture and jade in aspects of artistic and cultural value and manifests the importance of jade in Chu culture.

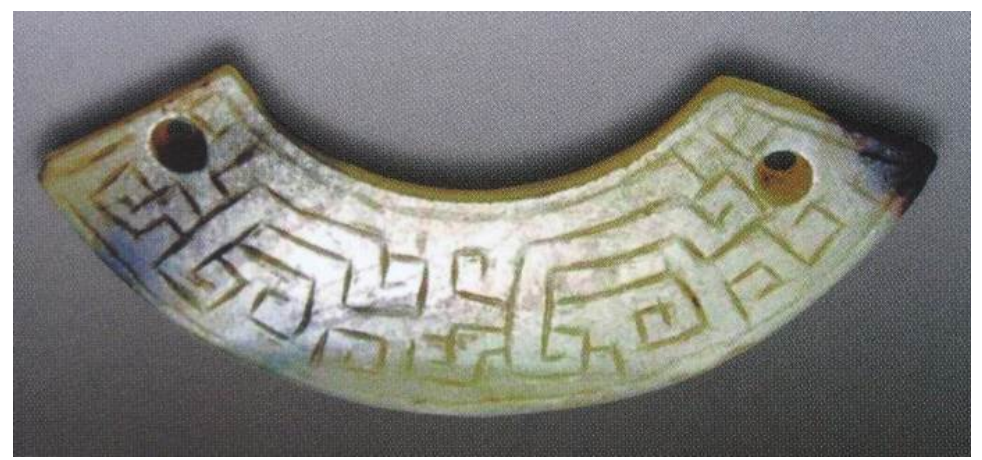

3 : Yu Juan (Temple of Xichuan under the Warring States Chu tomb)

The jade pattern of Chu state is quite artistic and shows prominent artistic characteristics as well as value. In ancient times, jade does not only reflect culture of Chu, but also makes an integration between aesthetic values of culture and art, which implies pursuit for artistic beauty of Chu culture. The etiquette culture, as the foundation of Chu culture, is the core of cultural architect. Jade, usually bearing with itself rich connotation and implications. Various jade patterns and their respective artistic features as well as values presenting in etiquette culture of Chu, Serve as foundation of cultivation and development of culture. a The flow sense of jade is a crucial artistic feature of jade culture of Chu state, which highlights high quality and deep connotation of jade, shows Chu people's emphasis on ceremony and manifests Chu people's personalities and their perception over culture. What's more, such sense of flow, interpreting from the perspective of aesthetics, presents the artistic beauty and delicate workmanship of pattern design and jade carving, while from the perspective of culture, it unfolds the "personalized beauty". Therefore, jade of Chu state bears both artistic and cultural connotations.

\section{Conclusion}

Of various cultural patterns of Chu state at Pre-Qin period, cultural connotations brought by 
Chinese jade culture exert fundamental influence to inheritance and progress of traditional culture. In light of cultural and artistic features of jade at that times, artistic values of those exquisite patterns and expert workmanship can be perceived. National spirits, traits and personalities reflected by jade to some extent show that jade plays a critical role in culture inheritance and advancement. Studies on cultural and development of traditional culture in modern times at spiritual and artistic levels as well as directly impacts the progress of society and culture.

\section{References}

[1] Lin Lin: a brief talk on Zhou Lizhong's jade system, Tai LAN world: late, 2014,page16-17

[2] Shen Wei, Li Xiusong: Jade Culture and the process of prehistoric civilization -- historical evidence of Jianghuai Region, Journal of Chongqing University(Social Science Edition) | J Chongqing Univ,2014,page146-151

[3] Luo Yue, Zhang Qiao: the emergence and decline of Dongzhou grain roll shaping jade decoration, New ARTS,2014,page29-35 